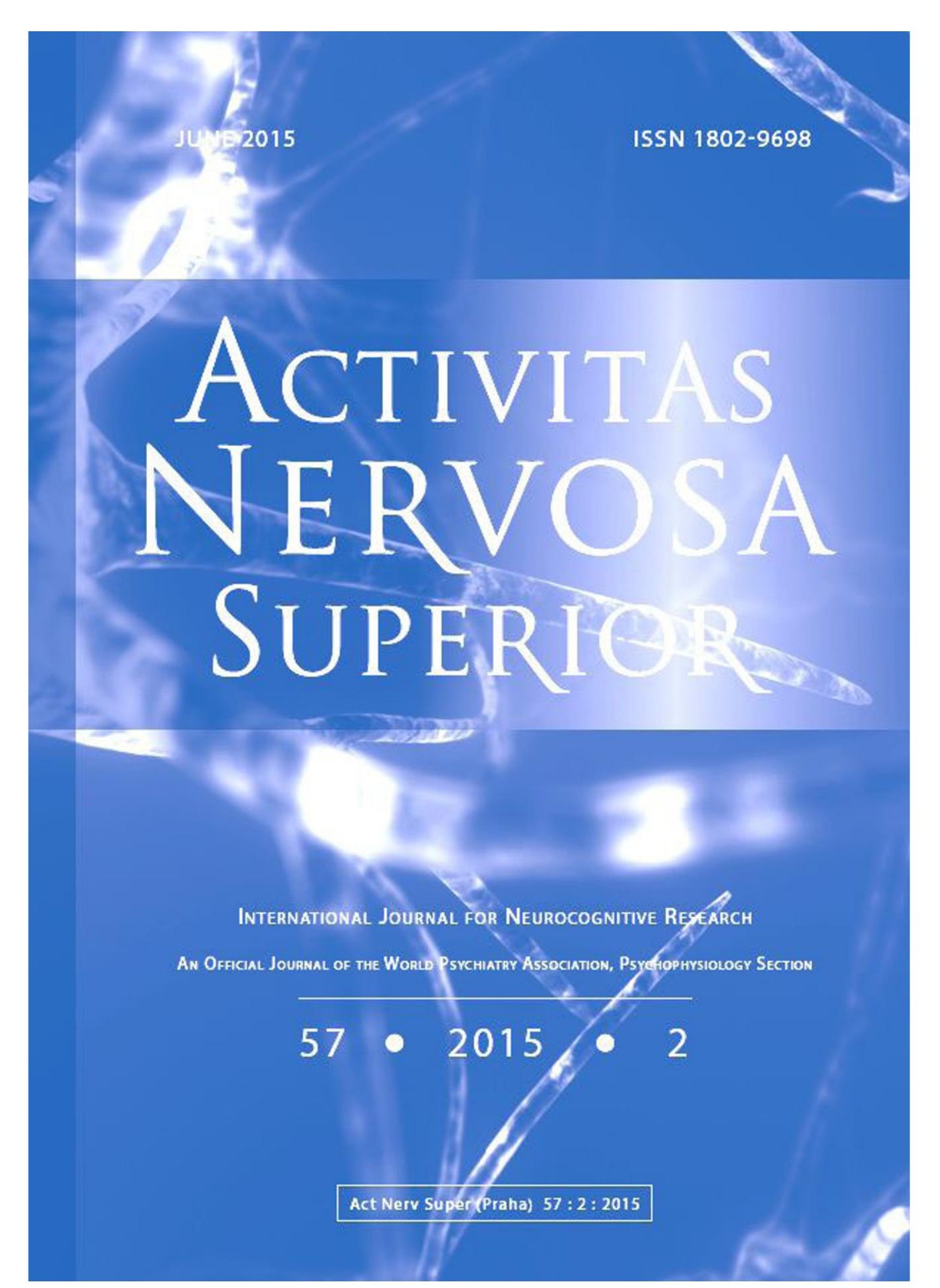

ANS: Journal for Neurocognitive Research Homepage:

www.activitas.org

\title{
RELATIONSHIP OF BODY IMAGE AND SELF- ESTEEM IN ADOLESCENTS WITH DIFFERENT TYPES OF CONSTITUTIONAL DEVELOPMENT: PRELIMINARY RESUlTS
}

\author{
Alona Tiunova* \\ Department of Applied Psychology, Education Management University, \\ Kiev, Ukraine
}

\begin{abstract}
This study evaluated the peculiarities of relationships of body image and self-esteem of Ukrainian adolescents with different types of constitutional development. In a school-based cross-sectional survey, a total of 250 adolescents were recruited. They filled out self-completing questionnaires on body image, body parts ranking, self-esteem, personal qualities and related factors. The results suggest that body image in the consciousness of a teenager defines his personal characteristics, level of self-esteem, the scope of internal conflicts and specific features of emotional reactions on the environment.
\end{abstract}

Key words: Body image; Self-esteem; Adolescent; Constitutional development; Body parts

\section{INTRODUCTION}

The beliefs and evaluations people hold about themselves determine who they are, what they can do and what they can become (Burns, 1982). Some people struggle with their self-esteem and body image when they begin puberty because it is a time when the body goes through many changes.

Since puberty, by its very nature, is associated with weight gain, adolescents frequently experience dissatisfaction with their changing bodies. Socio-cultural agents, such as peers, parents, and the media are also hypothesized to contribute to lower self-esteem (TantleffDunn \& Gokee, 2004). Family life can sometimes positively influence development of adolescent's body image. Approval and support, especially from parents and peers, and selfperceived competence in domains of importance are the main determinants of self-esteem (Harter, 1999). For instance, in their prospective study among young adolescents, Garber and Flynn (2001) found that negative self-worth develops as an outcome of low maternal acceptance, a maternal history of depression and exposure to negative interpersonal contexts.

Low self-esteem and negative body image have been reported as the most important factors for risk-taking behavior (Kristin, 2011; Neumark-Sztainera et. al., 2006; Rawana \& Morgan, 2014). Teenagers with low self-esteem often fall victim to a variety of unhealthy

*Correspondence to: Alona Tiunova, e-mail: tarast25@gmail.com

Received May 12, 2015; accepted June 23, 2015; Act Nerv Super 57(2), 81-86; ISSN-1802-9698 
behaviors and may become more susceptible to peer pressure, while others may remain more self-centered (Clemens et al., 2004). So most likely, the two main pillars of the perception of someone's appearance are body image and self-esteem (Ching et al., 2003).

Body image is defined as "the perception of overall physical appearance" (Pokrajac-Bulian \& Zivcic-Becirevic, 2005), (estimated size of the body) and other writers allude to its attitudinal component, focusing on satisfaction with, and evaluation of the body (Grogan, 2008). It is considered to be a major component of global self-esteem. Moreover, body dissatisfaction, while a component of body image disturbance, consists of dysfunctional, negative beliefs about one's weight and shape (Crowther \& Williams, 2011). Both body image and body dissatisfaction are subjective concepts and potentially open to change over time through social influence and self-reassessment (Grogan, 2008). A large number of longitudinal studies investigate body dissatisfaction as a part of a larger concept of body image (Bucchianeri et al., 2013; de Guzman \&Nishina, 2014; Paxton, Eisenberg \& Neumark-Sztainer, 2006; Mellor et al., 2013). Besides, dissatisfaction related to body image is treated as an important predictor for developing serious problems in psychological and physical functioning, such as eating disturbances, overweight incidence, dieting and unhealthy weight control (Wilson, Latner \& Hayashi, 2013; Mäkinen et al., 2012;. Calzo et al., 2012; Evans et al., 2013; Wojtowicz \& von Ranson, 2012).

People's concepts and feelings about themselves are generally labeled as their self-concept and self-esteem. Self-esteem is the evaluative and affective dimension of the self-concept, and is considered as equivalent to self-regard, self-estimation and self-worth (Harter, 1990). Selfesteem refers to a person's global appraisal of his/her positive or negative value, based on the scores a person gives him/herself in different roles and domains of life (Rogers, 1981; Hazel, Nurius, 1986).

These powerful, inner influences provide an internal guiding mechanism, steering and nurturing individuals through life (Seligman \& Csikszentmihalyi, 2000; Bandura, 1986; Bowlby, 1980; Rutter, 1992; Harter, 1986).

Empirical studies over the last 15 years indicate that self-esteem is an important psychological factor contributing to health and quality of life (Evans, 1997). Recently, several studies have shown that subjective well-being significantly correlates with high self-esteem (Zimmerman, 2000). Self-esteem has been found to be the most dominant and powerful predictor of happiness (Furnham \& Cheng, 2000). Indeed, while low self-esteem leads to maladjustment, positive self-esteem, internal standards and aspirations actively seem to contribute to 'well-being' (Garmezy, 1984; Glick \& Zigler, 1992).

However, very little is known about the relationship of body image and self-esteem at the population level among adolescents with different types of constitutional development. It should be mentioned that similar studies have not been conducted in Ukraine. This crosssectional study was designed to explore different types of constitutional development as factors associated with body image and self-esteem among Ukrainian adolescents. It especially investigates the associations among body image, self-esteem and constitutional development.

\section{METHODS}

\subsection{Participants}

Of a total of 250 adolescents (135 girls and 115 boys; Mean age $=14.8$ years, SD $=0.7$ ) were recruited from five middle schools located in Kiev city, the capital of Ukraine, and its region. No statistical difference was observed between the participants of socio-economic condition ( $p$ $=0.53$ ) or parental education ( $p=0.16$ for mothers; $p=0.74$ for fathers). The target schools volunteered to participate in the study, and we selected them to represent typical Ukrainian public schools in the urban area. After gaining approval, researcher visited the schools, explained the purpose of the study to the pupils and teachers, and gained their consent. The 
researcher also sent the parents letters introducing the purpose of the study. The letter included a statement that parents could freely refuse to respond if they did not agree with the purpose of the study.

\subsection{Psychometric assessment}

We used Apprehension and body parts ranking method (Burlachuck, 2007) to reveal conscious and unconscious, rational and emotional value of mentioned various parts of the body, as well as possible areas of conflict when comparing conscious and unconscious significance of a body of subjects. The subjects were offered for 2 minutes to remember and write parts of the body, and then rank them in importance. Time limit is set for subjects to record parts of the body at once, in the order in which they have them in mind.

Processing results: The place of the body parts in a row and their rank of importance are recorded in the table. Then their differences are calculated, indicating a degree of awareness of the importance of different parts of the body value for participants in his body image. Similarly, the average for a group rank and place are calculated that indicates the importance of value of studied different body parts for the sample.

The questionnaire of self-attitude by V. Stolin and S. Pantylyeyev (Burlachuck, 2007) was used for profound study of the sphere of self-consciousness, which includes a variety of (cognitive, dynamic, integrated) aspects. This method was created by Russian scientist S. Pantylyeyev in 1989 in accordance with hierarchical model of the structure of self-esteem, developed by another Russian scientist V. Stolin. The advantage of this method is that it gives good results in the identification of intrapersonal conflicts that have a direct influence on the formation of adolescent's body image. This fact conditioned the choice of this method for our research.

This version of the questionnaire reveals three levels of self-esteem that differ in terms of generalization: 1. Global self-esteem. 2. Self-esteem differentiated by self-respect, autosympathy, self-interest and expectations about attitude towards himself. 3 . The level of specific actions (preparedness) in relation to own "I".

The questionnaire includes the following scale: $S$ - measures the integral sense "for" or "against" his own "I"; I - self-esteem; II - autosympathy; III - expectations of a positive attitude from others; IV - self-interest; 1 - self-confidence; 2 - attitude of others; 3 - self-acceptance; 4 self-consistency; 5 - self-incrimination; 6 - self-interest; 7 - self-understanding.

\subsection{Data analysis}

Statistical analyses were conducted using Spearman correlations (the received data have not normal distribution) and descriptive statistics. The data processing was carried out using version 11.5 computer program Statistical Package for the Social Science (SPSS) for Windows.

\section{RESULTS}

By the results of the questionnaires we investigated correlation dependence and relationship between different aspects of body image and self-esteem in general. Evaluation components found out a large number of correlations with the results by the scales of self-attitude. The self-esteem of external component of body image has a positive correlation dependence of integral self-attitude $(\mathrm{r}=0.45)$, self-estimation $(\mathrm{r}=0.44)$, autosympathy $(\mathrm{r}=0.36)$, the expected attitude of others $(r=0.28)$, self-interest $(r=0.36)$, self-confidence $(r=0.45)$, self-acceptance $(r$ $=0.33)$ with $(\mathrm{p}<0.009)$.

The expected evaluation of external component of body image by the participants has correlation dependence of data from self-esteem scales: integrated self-esteem $(r=0.3)$, selfrespect $(r=0.44)$, the expected attitude $(r=0.3)$, self-confidence $(r=0.45)$, self-acceptance $(r=$ 
$0.33)$, self-interest $(\mathrm{r}=0.36)$ with $(\mathrm{p}<0.009)$. Thus, the more differentiated body image is connected with lower self-esteem, self-acceptance and self interest.

According to the received results the body image ideal evaluation is correlatively dependent on the integral self-attitude $(r=0.33)$, self-esteem $(r=0.3)$, self-confidence $(r=0.37)$ with $(p<0.009)$. Besides, it was established the correlation dependence of the degree of satisfaction with body image and data by self-esteem scale $(\mathrm{p}<0.009)$ and integral selfattitude $(r=0.4)$, self-esteem $(r=0.33)$, autosympathy $(r=0.36)$, expected attitude $(r=0.32)$, self-interest $(r=0.3)$, self-confidence $(r=0.34)$, self-acceptance $(r=0.3)$, self-blame $(r=-0.31)$, self-understanding $(\mathrm{r}=0.4)$.

\section{CONCLUSIONS}

Examination of the relationship of body image and self-esteem of Ukrainian adolescents with different types of constitutional development revealed that adolescent's evaluation of his/her own body image has a significant impact on the self-esteem and, moreover, the self-esteem significantly affects the adolescents' evaluation of their appearance. These findings, for the most part, are consistent with the results of previous longitudinal studies (e.g. Cantin \& Stan, 2010; Paxton et al., 2006; Tiggeman, 2005) which prove that self-esteem is closely related to body image. The received results also refine the results of one study (Dion et al., 2015) that self-esteem is more connected with factors associated with physical appearance compared with body dissatisfaction. In this context the results of our research proved that the main factor which influences adolescent's self-esteem is social importance of certain features of appearance. This fact suggests that features of the social environment (i.e., peers and family members) may considerably influence the formation of adolescent's self-esteem, which is directly associated with body image.

Concurrent with previous research (Paxton, et al., 2006), having low self-esteem may cause that adolescents may be more vulnerable to real or perceived criticism (e.g., weight teasing) and a pressure to achieve the ideal body type (e.g., dieting), thereby contributing to negative body image (Litteton \& Ollendick, 2003). These data implicate that certain evaluation of own appearance leads to appropriate self-esteem and helps an adolescent to establish relationships with the environment. Besides, body image can refer to image satisfaction-dissatisfaction, feelings about one's appearance, concerns about various body parts and physical characteristics, etc. (Dion et al., 2015). From the perspective of clinical work, the findings of our research highlight the importance of strengthening the self-esteem of adolescents which may influence the formation of positive body image and consequently to lower the risk of developing clinical eating disorders (O’Dea, 2004).

\section{REFERENCES}

Bandura, A. (1986). Social Foundations of Thought and Action: A Social Cognitive Theory. Englewood Cliffs: Prentice-Hall.

Bowlby, J. (1980). Attachment and Loss III: Loss Sadness and Depression. London: Hogarth Press.

Bucchianeri, M., Arikian, A., Hannan, P., \& Eisenberg, M. (2013). Body dissatisfaction from adolescence to young adulthood: Findings from a 10-year longitudinal study. Body Image, 10, 1-7.

Burlachuk L.F. (2007). Dictionary of psychodiagnostics (Словарь-справочник по психодиагностике). Saint Petersburg: Piter.

Burns, R. (1982). Self Concept-Developing and Education. Dorchester: Dorset Press.

Calzo, J., Sonneville, K., Haines, J., Blood, E., Field, A., \& Austin, S. (2012). The development of associations among body mass index, body dissatisfaction, and weight and shape concern in adolescent boys and girls. Journal of Adolescent Health, 51, 517-23. 
Cantin, S., \& Stan, S. (2010). Peer relations in adolescence as risk factors for body image dissatisfaction (Les relations avec les pairs à l'adolescence comme facteurs de risque de l'insatisfaction à l'égard de l'image corporelle). Canadian Journal of Behavioral Science, 42, 116-126.

Ching, S., Thoma, A., McCabe, R., \& Antony, M. (2003). Measuring Outcomes in Aesthetic Surgery: A Comprehensive Review of the Literature. Plastic \& Reconstructive Surgery, 11, 469-480.

Clemens, M., Hosman, M., Schaalma, H., \& Nanne, K. (2004). Self-esteem in a broad-spectrum approach for mental health promotion. Health Education Research, 19, 357-372.

Crowther, J., \& Williams, N. (2011). Body image and bulimia nervosa. In Cash T. F, \& Smolak L. (Eds.), Body Image: A Handbook of Science, Practice, and Prevention (pp. 288-295). NY: Guildford Press.

Dion, J., Blackburn, M., Auclair, J., Laberge, L., Veillette, S., Gaudreault, M., Vachon, P., Perron M., \& Touchette E. (2015). Development and aetiology of body dissatisfaction in adolescent boys and girls. International Journal of Adolescence and Youth, 20, 151-166.

Evans, D. (1997). Health promotion, wellness programs, quality of life and the marketing of psychology. Canadian Psychology, 38, 1-12.

Evans, E., Tovee, M., Boothroyd, L., \& Drewett, R. (2013). Body dissatisfaction and disordered eating attitudes in 7- to 11-year-old girls: testing a sociocultural model. Body Image, 10, 8-15.

Furnham, A., \& Cheng, H. (2000). Lay theories of happiness. Journal of Happiness Studies, 1, 227-246.

Garber, J., \& Flynn, C. (2001). Predictors of depressive cognitions in young adolescents. Cognitive Theory and Research, 25, 353-376.

Garmezy, N. (1984). The study of stress and competence in children: a building block for developmental psychopathology. Child Development, 55, 97-111.

Glick, M., \& Zigler, E. (1992). Premorbid competence and the courses and outcomes of psychiatric disorders. In Rolf J., Masten A., Cicchetti D., Nuechterlein K,. \& Weintraub S (Eds). Risk and Protective Factors in the Development of Psychopathology (pp. 497-513). Cambridge: Cambridge University Press.

Grogan, S. (2008). Body Image: Understanding Body Dissatisfaction in Men, Women and Children. London: Routledge.

de Guzman, N., \& Nishina, A. (2014). A longitudinal study of body dissatisfaction and pubertal timing in an ethnically diverse adolescent sample. Body Image, 11, 68-71.

Harter, S. (1990). Causes, correlates and functional role of global self worth: a life span perspective. In Kollgian, J., \& Sternberg R. (Eds.). Perceptions of Competence and Incompetence across Life Span. New Haven: Yale University Press, 67-98.

Harter, S. (1986). Processes underlying the construction, maintenance and enhancement of the selfconcept in children. In Suls J., \& Greenwald A. (Eds.) (pp. 137-181). Psychological Perspectives on the Self, 3 .

Harter, S. (1999). The Construction of the Self. A Developmental Perspective. NY: Guilford Press.

Hazel, M., \& Nurius, P. (1986). Possible selves. American Psychologist, 41, 954-969.

Kristin, D. (2011). Self-Compassion, Self-Esteem, and Well-Being. Social and Personality Psychology Compass, 5(1), 1-12.

Litteton, H., \& Ollendick. T. (2003). Negative body image and disordered eating behavior in children and adolescents: What places youth at risk and how can these problems be prevented? Clinical Child and Family Psychology Review, 6(1), 51-66.

Mäkinen, M., Puukko-Viertomies, L., Lindberg, N., Siimes, M., \& Aalberg, V. (2012). Body dissatisfaction and body mass in girls and boys transitioning from early tomid-adolescence: additional role of selfesteem and eating habits. BMC Psychiatry, 10, 12-35.

Mellor D., Waterhouse, M., Mamat, N., Xu X, Cochrane, J., McCabe, M., Ricciardelli, L. (2013). Which body features are associated with female adolescents' body dissatisfaction? A cross-cultural study in Australia, China and Malaysia. Body Image, 23, 54-61.

Neumark-Sztainera, D., Levineb, M., Paxtonc, S., Smolakb, L., Pirand, N., \& Wertheimc, E. (2006). Prevention of Body Dissatisfaction and Disordered Eating: What Next? Eating Disorders: The Journal of Treatment \& Prevention, 4, 265-285.

Neumark-Sztainer, D., Wall, M., Story, M., Standish, A. (2012). Dieting and unhealthy weight control behaviors during adolescence: associations with 10-year changes in body mass index. Journal of Adolescent Health, 50, 80-6.

O'Dea, J. (2004). Evidence for a self-esteem approach in the prevention of body image and eating problems among children and adolescents. Eating Disorders, 12, 225-239.

Paxton, S., Eisenberg, M., \& Neumark-Sztainer D. (2006). Prospective predictors of body dissatisfaction in adolescent girls and boys: A five-year longitudinal study. Developmental Psychology, 42, 888-899.

Pokrajac-Bulian, A., \& Zivcic-Becirevic I. (2005). Locus of control and self-esteem as correlates of body dissatisfaction in Croatian university students. European Eating Disorders Review, 13, 54-60. 
Rawana, J., \& Morgan, A. (2014). Trajectories of depressive symptoms from adolescence to young adulthood: the role of self-esteem and body-related predictors. Journal of Youth and Adolescence, 43, 597-611.

Rogers, T. (1981). A model of the self as an aspect of the human information processing system. In Canton N., Kihlstrom J. (Eds.) Personality, Cognition and Social Interaction (pp.193-214). Hillsdale: Erlbaum.

Rutter, M. (1992). Psychosocial resilience and protective mechanisms. In Rolf J., Masten A., Cicchetti D., Nuechterlein K., \& Weintraub S. (Eds.). Risk and Protective Factors in the Development of Psychopathology (pp. 181-214). Cambridge: Cambridge University Press.

Seligman, M., \& Csikszentmihalyi, M. (2000). Positive psychology: an introduction. American Psychologist, $55,5-14$.

Shomaker, L., \& Furman, W. (2009). Interpersonal influences on late adolescent girls' and boys' disordered eating. Eating Behaviors, 10(2), 97-106.

Tantleff-Dunn, S., \& Gokee, J. (2004). Interpersonal influences on body image development. In: Cash T., \& Pruzinsky T. Body Image: A Handbook of Theory, Research, and Clinical Practice. (pp. 108-116). NY: Guilford Press.

Tiggemann, M. (2005). Body dissatisfaction and adolescent self-esteem: Prospective findings. Body Image, 2, 129-135.

Wilson, R., Latner, D., \& Hayashi, K. (2013). More than just body weight: the role of body image in psychological and physical functioning. Body Image, 10, 644-7.

Wojtowicz, A., \& von Ranson, K. (2012). Weighing in on risk factors for body dissatisfaction: a one-year prospective study of middle-adolescent girls. Body Image, 9, 20-30.

Zimmerman, S. (2000). Self-esteem, personal control, optimism, extraversion and the subjective wellbeing of Midwestern university faculty. Dissertation Abstracts International B: Sciences and Engineering, $60,3608$. 